\title{
Phenological Study of Chinese Jujube Trees Using Biologische Bundesanstalt, Bundessortenamt and CHemische Industrie (BBCH) Scale
}

\author{
Sundar Sapkota ${ }^{1}$, Sanjib Sapkota ${ }^{1}$, Sen Wang ${ }^{2}$ and Zhiming Liu ${ }^{1}$ \\ ${ }^{1}$ Department of Biology, Eastern New Mexico University, Portales, USA \\ ${ }^{2}$ College of Forestry, Central South University of Forestry and Technology, China
}

\begin{abstract}
Chinese jujube is a perennial fruit tree, famous for its nutritional and medicinal value. However, there is a lack of information on its growth cycle. The study was carried out in Portales, New Mexico, from 2018-2019, to define the phenophases of Chinese jujube according to $\mathrm{BBCH}$ scale. We observed eight major growth stages for Chinese jujube: bud growth, leaf formation, leaf growth, shoot growth, formation of inflorescence, flowering, fruit formation, growth and development, fruit maturation, and winter dormancy. The developed code could help jujube farmers perform orchard management practices such as pruning, water and fertilizer management, pest control, and harvesting.
\end{abstract}

Keywords

BBCH scale, Growth stages, Jujube, Phenology

\section{Introduction}

Jujube (Ziziphus jujuba) is a deciduous fruit tree belonging to the family Rhamnaceae. It grows well in arid and semi-arid regions where other fruit trees under perform [1]. Jujube is native to China and distributed in over 47 countries worldwide, with the highest concentrations in Asia, Europe, Africa, and North America [2]. The tree is very hardy, can tolerate drought and temperatures as low as $-38^{\circ} \mathrm{C}[3,4]$. Jujube is a perennial tree, growing 5-10 $\mathrm{m}$ high with zigzagged branches. Branches in young plants consist of paired spines (straight or curvy), but older trees usually lack spines [1]. Leaves are green, small, simple, alternate, and ovate to lanceolate in shape. The inflorescence is a cyme and consists of 2-13 flowers. Jujube flowers vary from $3.5-10 \mathrm{~mm}$ in diameter $[1,5]$. Flowers are greenish-white to yellow, shortstalked, and produced at the axil of leaves. The fruit type is a drupe having three layers: epicarp, mesocarp, and endocarp. Fruits are reddish brown, ellipsoid to elongate, often round shape. Fruit diameter varies from $1.4-4 \mathrm{~cm}$ depending on the cultivars [1]. Jujube tree has multiple benefits such as wide adaptability, source of foods (fruits, wine, tea), fodder, and nectar $[6,7]$. The fruit contains high amounts of vitamins $(A, B, C)$, phenols and antioxidants [8]. Jujube fruits are famous for their medicinal value. Different parts of the jujube plant, such as bark, leaf, roots, fruit, and seed have been commonly used as sources of crude drugs for several health problems, including cancer [9].

Phenology is the study of life cycle phases of an organism in its habitat throughout the year [10]. The knowledge of different life stages of a particular plant species provides better ideas on correct timing of orchard management especially, training, pruning, water, fertilizer and pesticides application, irrigation scheduling, pollination management, flower, and fruit thinning, and harvesting [11-13]. The Biologische Bundesanstalt, Bundessortenamt and $\mathrm{CHemische}$ Industrie $(\mathrm{BBCH})$ scale is useful to explain the growth stages of plants $[14,15]$. Generally, BBCH scale consists of two digits code to define life events of plant species. The major growth stage is indicated by the first digit which scaled from 0-9. Similarly, the second digit represents secondary life phases $[13,14,16]$.

Several researchers had successfully employed the $\mathrm{BBCH}$ scale to study life events of different fruit plants. The examples include grapevine [17], citrus [18], kiwi [12], mango [13], guava [19], avocado [20], sweet cherry [21], and pineapple [22]. Despite the economic and ecological significance, the phenological stages of Chinese jujube have not been well un-

*Corresponding author: Sundar Sapkota, Department of Biology, Eastern New Mexico University, Portales, NM 88130, USA

Accepted: March 26, 2020

Published online: March 28, 2020

Citation: Sapkota S, Sapkota S, Wang S, et al. (2020) Phenological Study of Chinese Jujube Trees Using Biologische Bundesanstalt, Bundessortenamt and CHemische Industrie (BBCH) Scale. J Hortic Sci Res 3(1):68-73 
Citation: Sapkota S, Sapkota S, Wang S, et al. (2020) Phenological Study of Chinese Jujube Trees Using Biologische Bundesanstalt, Bundessortenamt and CHemische Industrie (BBCH) Scale. J Hortic Sci Res 3(1):68-73

derstood. To date, no particular phenological scale has been established for the jujube plant. Southern regions of New Mexico are potential regions for farming jujube, but the lack of information about crop species have restricted production. A very few studies have been conducted using jujube plants in these regions. Sapkota, et al. [23] reported the best size of jujube suckers (height: $50-100 \mathrm{~cm}$; diameter: $0.36-0.75 \mathrm{~cm}$ ) in the semi-arid region of New Mexico and suggested the need of more plant-ecological studies. The research about phenological stages is critical, not only for introducing a crop to a new region but also for enhancing crop production. Thus, this study aims to describe phenological growth stages of Chinese jujube (Ziziphus jujuba) using BBCH scale in Portales, New Mexico, USA.

\section{Materials and Methods}

The study was conducted in Portales, New Mexico (latitude: $34^{\circ} 11^{\prime} 10.29^{\prime \prime} \mathrm{N}$; longitude: $103^{\circ} 20^{\prime} 3.83^{\prime \prime} \mathrm{W}$, elevation: $1222 \mathrm{~m}$ ), which represents the south western USA. The experimental area has hot summer (May to August), less rainfall, and mild winter (October to January). The minimum, maximum, mean annual temperatures, and rainfall of the study area in 2018 were $7{ }^{\circ} \mathrm{C}, 25^{\circ} \mathrm{C}, 16{ }^{\circ} \mathrm{C}$, and $367 \mathrm{~mm}$ whereas in 2019 were $6{ }^{\circ} \mathrm{C}, 24^{\circ} \mathrm{C}, 15^{\circ} \mathrm{C}$, and $440 \mathrm{~mm}$, respectively. Orchard soil was sandy loam (pH: 6.95) with potentially mineralizable carbon and nitrogen values 7.64 and $135.96 \mathrm{mg} / \mathrm{kg}$, respectively. Different growth stages of Chinese jujube trees were closely observed using the BBCH scale during 20182019. We recorded data at three-day intervals.

\section{Results}

The growth cycle of Chinese jujube consisted different stages between bud growth and winter dormancy (Table 1).

Table 1: Phenological growth stages of Ziziphus jujuba (BBCH scale).

\begin{tabular}{|l|l|}
\hline BBCH scale & Growth stages \\
\hline Growth stage 0: & Bud growth \\
\hline 00 & Leaf bud in winter dormancy \\
\hline 01 & Bud started to swell \\
\hline 03 & Bud swelling completed \\
\hline 07 & Bud sprouting begin \\
\hline 09 & Bud shows green tips \\
\hline
\end{tabular}

Growth stage 1: Leaf formation and growth

\begin{tabular}{|l|l|}
\hline 10 & Leaf $(10 \mathrm{~mm})$ emerge from leaf buds \\
\hline 11 & Opening of first leaf \\
\hline 15 & Unfolding of several leaves \\
\hline 19 & Full growth of first leaves \\
\hline Growth stage 3: & Shoot growth \\
\hline 31 & Beginning of shoot growth \\
\hline 32 & 20\% of shoot growth \\
\hline 33 & 30\% of shoot growth \\
\hline 39 & $90 \%$ of shoot growth \\
\hline Growth stage 5: & Formation of inflorescence \\
\hline
\end{tabular}

\begin{tabular}{|c|c|}
\hline 51 & Enlargement of the inflorescence buds \\
\hline 53 & Buds opened (greenish buds observed) \\
\hline 54 & Green scales covered inflorescence \\
\hline 55 & $\begin{array}{l}\text { Appearance of flower buds (not fully open), } \\
\text { opening of green scales }\end{array}$ \\
\hline 56 & $\begin{array}{l}\text { Flowers started to separate, sepals not fully } \\
\text { expanded }\end{array}$ \\
\hline 57 & $\begin{array}{l}\text { Opening of sepals, white petal tips appeared } \\
\text { (closed) }\end{array}$ \\
\hline 59 & Opening of flower petals \\
\hline \multicolumn{2}{|c|}{ Growth stage 6: Flowering } \\
\hline 60 & Opening of first flower \\
\hline 61 & Opening of almost $10 \%$ flowers \\
\hline 62 & Opening of almost $20 \%$ flowers \\
\hline 63 & Opening of almost $30 \%$ flowers \\
\hline 64 & Opening of almost $40 \%$ flowers \\
\hline 65 & $\begin{array}{l}\text { Complete flowering (opening of } 50 \% \text { flowers), } \\
\text { first petals drop down }\end{array}$ \\
\hline 67 & Withering and dropping of flowers and petals \\
\hline 69 & Flowering ended: Almost all petals dropped \\
\hline \multicolumn{2}{|c|}{ Growth stage 7: Fruit formation, growth and development } \\
\hline 71 & Rapid growth in fruit ovary; first fruit dropping \\
\hline 72 & $\begin{array}{l}\text { Tiny fruits surrounded by dying sepals, sepals } \\
\text { started to drop }\end{array}$ \\
\hline 73 & Heavy fruit dropping \\
\hline 75 & Fruit attained $50 \%$ of its final dimension \\
\hline 76 & Fruit attained $60 \%$ of its final dimension \\
\hline 77 & Fruit attained $70 \%$ of its final dimension \\
\hline 78 & Fruit attained $80 \%$ of its final dimension \\
\hline 79 & Fruit attained $90 \%$ of its final dimension \\
\hline \multicolumn{2}{|c|}{ Growth stage 8: Fruit and seed maturation } \\
\hline 81 & $\begin{array}{l}\text { Change in fruit color: From dark green to light } \\
\text { reddish brown }\end{array}$ \\
\hline 85 & $\begin{array}{l}\text { Fruit color advanced; becomes dark reddish } \\
\text { brown }\end{array}$ \\
\hline 87 & Picking stage for distant transportation \\
\hline 89 & $\begin{array}{l}\text { Fruit has excellent eating quality, final } \\
\text { harvesting stage }\end{array}$ \\
\hline \multicolumn{2}{|c|}{ Growth stage 9: Senescence, beginning of dormancy } \\
\hline 91 & End of shoot growth but leaves are green \\
\hline 92 & $\begin{array}{l}\text { Change in leaf color, green color started to } \\
\text { disappear }\end{array}$ \\
\hline 93 & Leaf dropping started \\
\hline 95 & Discoloring and dropping of about $50 \%$ leaves \\
\hline 97 & Dropping of all leaves \\
\hline 99 & Dormancy \\
\hline
\end{tabular}


Citation: Sapkota S, Sapkota S, Wang S, et al. (2020) Phenological Study of Chinese Jujube Trees Using Biologische Bundesanstalt, Bundessortenamt and CHemische Industrie (BBCH) Scale. J Hortic Sci Res 3(1):68-73

\section{Vegetative stage}

Reproductive stage

Maturity

Fruiting

Flowering

Inflorescence opening

Shoot growth

Leaf development

\section{Bud sprouting}

Leaf withering and

abscission

Winter dormancy

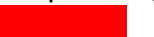

Apr

May

Jun

July

Aug Sept

Figure 1: Major growth stages of Chinese Jujube (BBCH scale) in Portales, New Mexico.

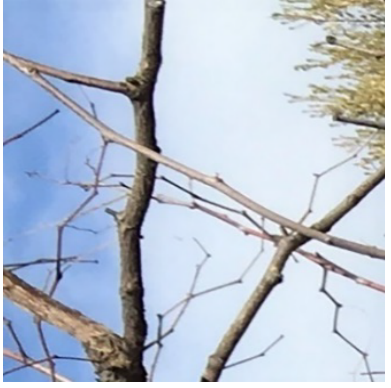

00

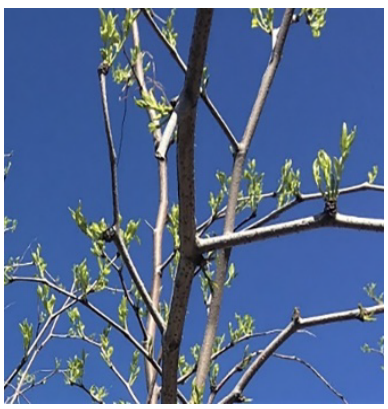

10

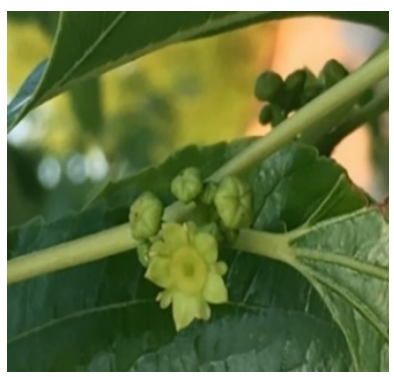

60

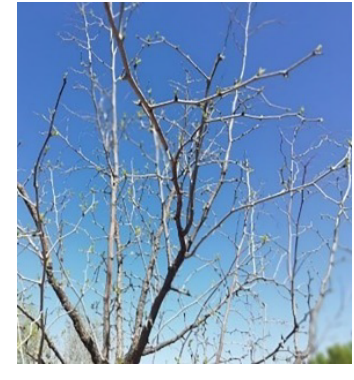

01

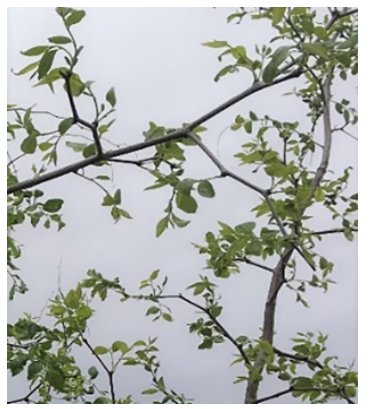

15

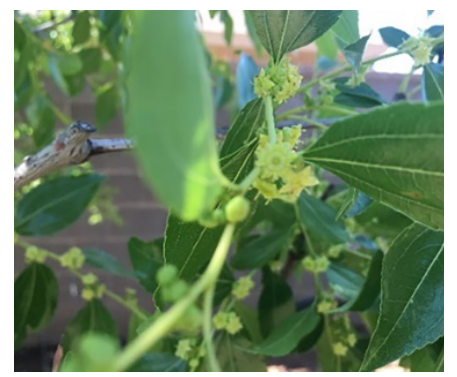

61

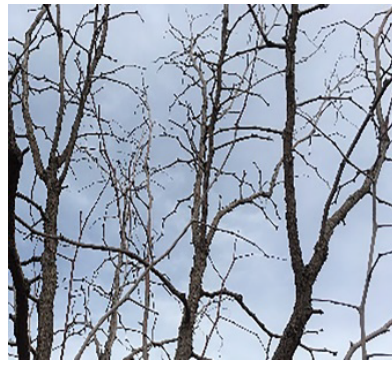

03

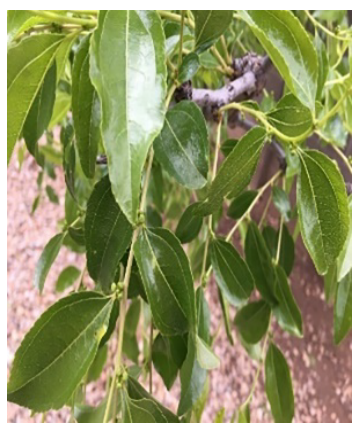

39

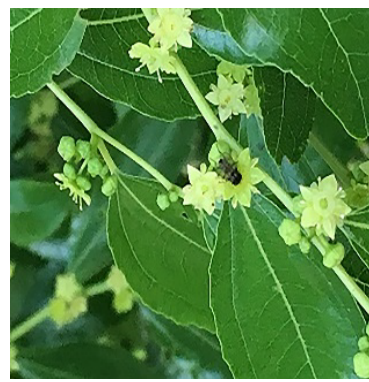

63

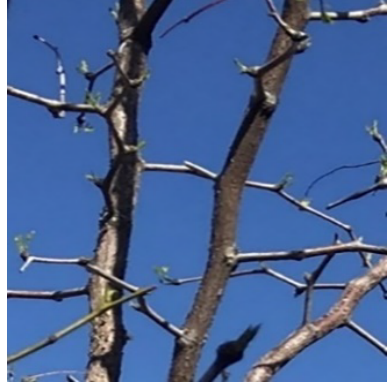

07

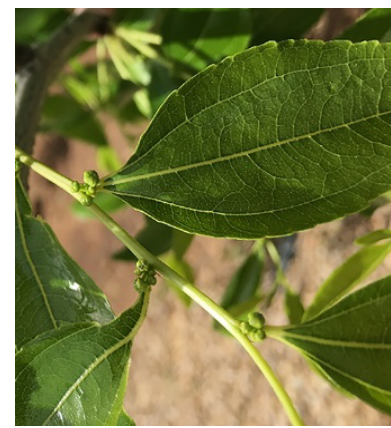

53

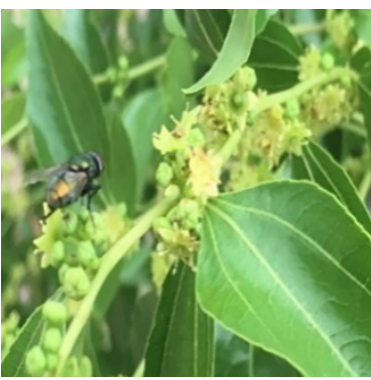

64 
Citation: Sapkota S, Sapkota S, Wang S, et al. (2020) Phenological Study of Chinese Jujube Trees Using Biologische Bundesanstalt, Bundessortenamt and CHemische Industrie (BBCH) Scale. J Hortic Sci Res 3(1):68-73

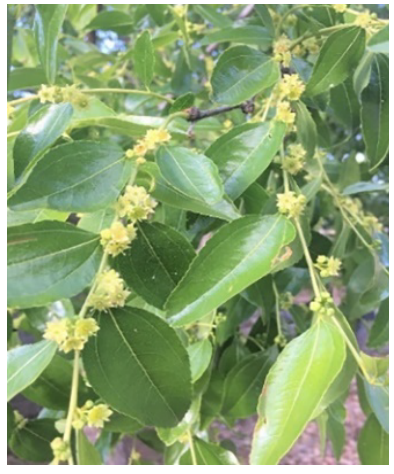

65

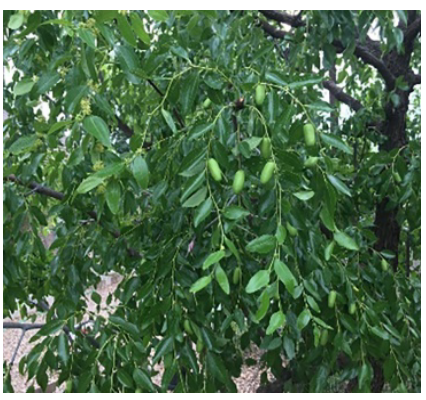

75

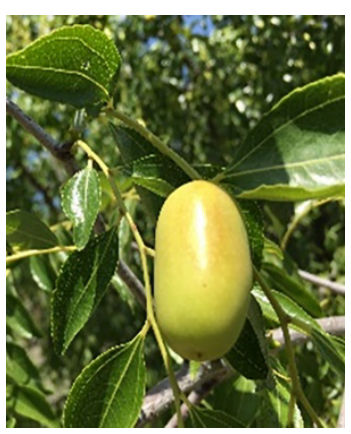

79

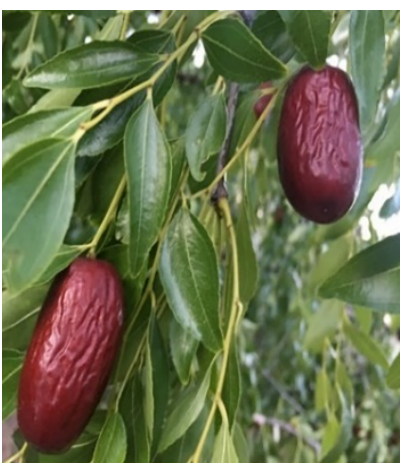

89

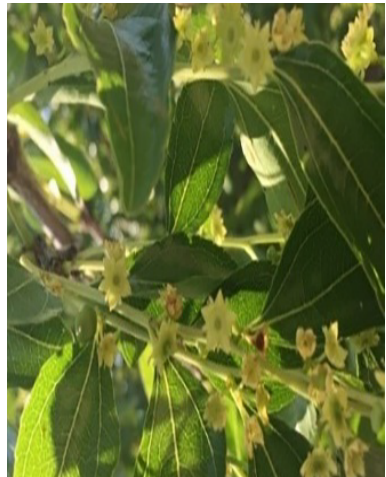

67

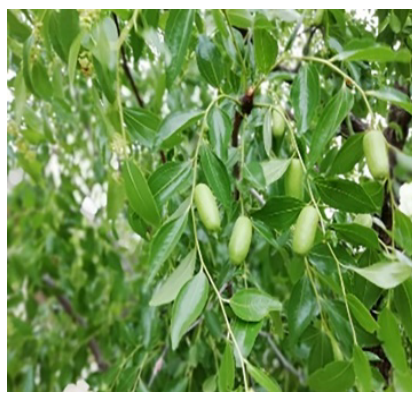

76

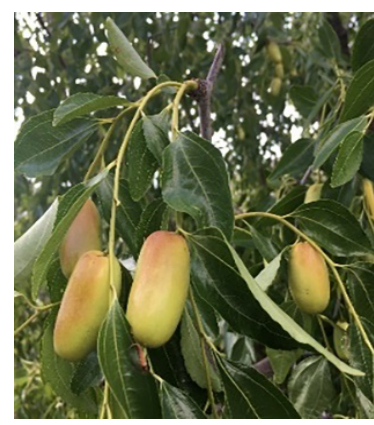

81

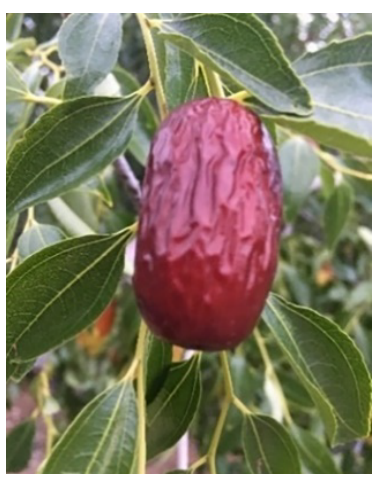

89

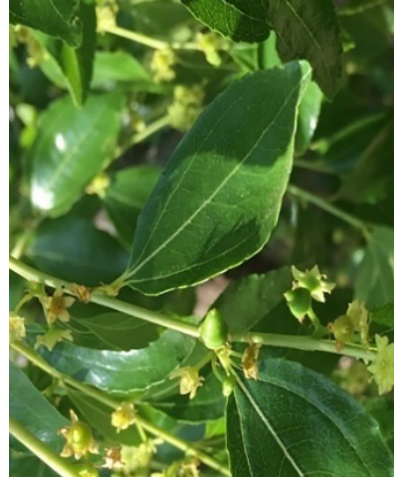

71

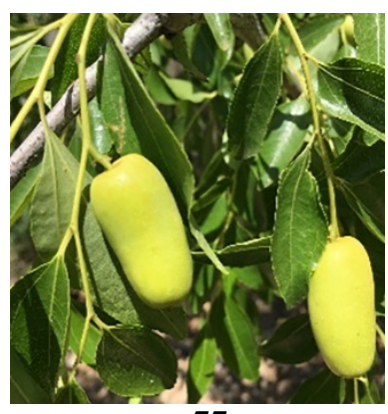

77

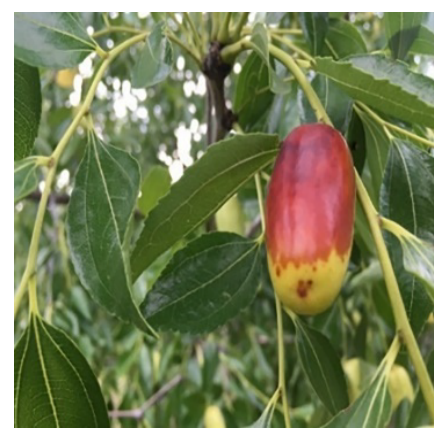

85

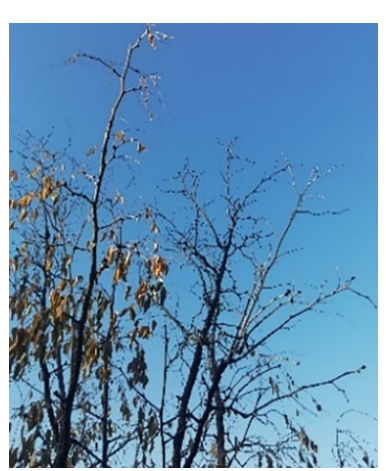

95

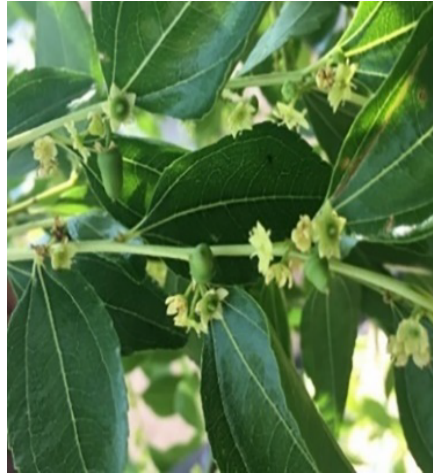

72

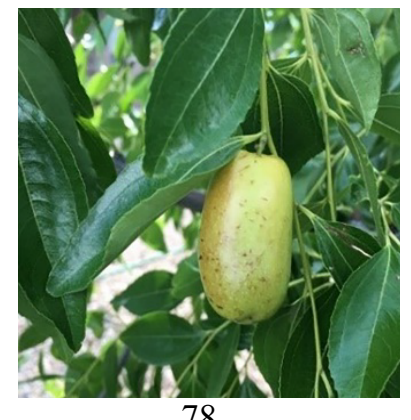

78

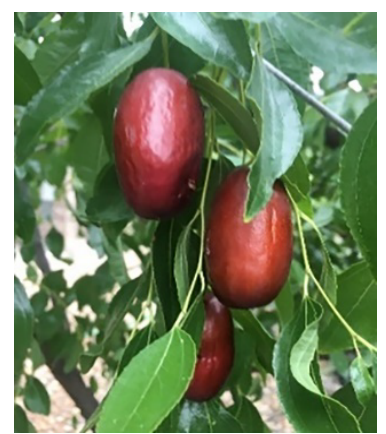

87

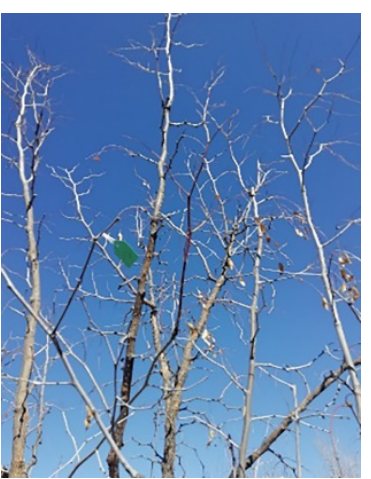

97

Figure 2: Phenological stages of Ziziphus jujube (BBCH scale).

Notably, eight major phenological stages were observed for Chinese jujube; three for vegetative stage, four for the reproductive phase and one for winter dormancy. The major stages were bud growth, leaf formation and growth, shoot growth, formation of inflorescence, flowering, fruit formation, growth and development, fruit maturation, and winter dormancy. Each major stage consisted several secondary stages. Interestingly, Chinese jujube had forty-six secondary growth phases in our location (Table 1). The major growth stages of Chinese jujube are as shown in Figure 1. The detail of phenological stages of Chinese jujube is as shown in Figure 2.

\section{Discussion}

The $\mathrm{BBCH}$ scale precisely describes morphological char- 
Citation: Sapkota S, Sapkota S, Wang S, et al. (2020) Phenological Study of Chinese Jujube Trees Using Biologische Bundesanstalt, Bundessortenamt and CHemische Industrie (BBCH) Scale. J Hortic Sci Res 3(1):68-73

acteristics of the jujube plant at different growth stages. The scale provides ideas to growers about critical growth phases and helps them to enhance fruit yield and quality. The vegetative growth of Chinese jujube consisted of three major stages: Bud, leaf, and shoot development at our location in Portales, New Mexico. The jujube growth consists of the formation of primary, secondary, mother bearing, and bearing shoots. The primary shoots formed the major structure of the plant, whereas secondary and bearing shoots were meant for reproduction. The vegetative growth of Ziziphus jujuba extends about two months, from mid-March to mid-May. During March, new green leaf tips started to emerge from the trees (7-10). The leaf continued to elongate and expand till it attains its typical size and color (bright green). Maximum shoot growth and maturation took place during mid-May (39). Notably, the vegetative growth stage proceeded in parallel with the reproductive stage. The reproductive stage started with the development of bearing shoots $(4,5)$ from the mother bearing shoots. The flowers were observed in a cluster on bearing shoot at the axils of the leaf from late May to July (60-67). The growing pattern of flower bud showed slower growth for the first week and then rapid growth and resulted in fully expanded flower within three to four weeks (63). The flowering cluster consisted of 10 to 12 flowers. Each flower was yellowish-white (60), about $2.5 \mathrm{~mm}$ in diameter, and consisted of five petals.

Furthermore, different secondary growth phases, including pollination, end of flowering, and flower fading, were observed. Pollination (64) happened all the time during the day by nectar-feeding housefly and bumblebee. When the first few flowers faded, the fruit began to develop (71). Flowering, fruit setting, and their growth proceeded in a parallel way. Fruit maturity was indicated by color change from green to reddish brown (81-85). The pericarp of the fruit turned dark reddish brown (87-89) within four to six weeks of the first color change (81). Kishore [14] reported identifying the correct time of harvest is essential to ensure fruit yield and quality. The best time to harvest jujube fruit for consumption is fully mature stage (87-89). After full maturation, fruits dried and wrinkled. Overall, in our location (Portales, New Mexico), jujube fruit reached the optimum harvesting stage during the mid to late September, about 10 to 12 weeks after fruit set. Delaying in harvesting causes fruits to drop and quality to deteriorate. After harvesting, leaves dropped down and plant entered into the winter dormancy (95-97). During late spring to early summer the trees started to produce suckers.

Effective management of fruit orchard includes several horticultural practices such as pruning, fertilizer application, irrigation scheduling, disease pest management, flower and fruit thinning, and timely harvest. All these activities require proper phenological knowledge [14]. In jujube orchard, pruning improves the passage of air and light. Furthermore, pruning encourages proper vegetative growth, thus increase fruit yield [24]. Pruning should be started at the beginning of spring season and can continue throughout the dormant season (stage 00). Liu [1] and Liu and Zhao [3] stated that pruning operations in jujube trees could be performed when tree is in growing or dormant phase. The dormant pruning involves removing weak, old, disease infected, and crowed shoots so that trees can produce satisfactory fruit yield and quality. During the summer season, crowded buds, shoots, and infected/damaged shoots should be removed. The best time for fertilizing jujube is immediately after fruit harvest to provide necessary nutrients. For jujube orchards, natural pollination mainly depends on bumblebees and houseflies [1]. Hand and machine pollination may not be feasible in the farmer's field, but farmers can apply natural pollinators (introduction of bee hives).

Moreover, $\mathrm{BBCH}$ scale is useful in dealing with phytopathological problems in jujube orchards. For example, witches broom, caused by phytoplasma, is the severe disease of jujube, where shoot appears as a witches broom, flower undergoes metamorphosis, and the tree dies 4-5 years early. The effective way to control witches broom disease is girdling the tree trunk after the bud break stage. This practice obstructs the pathogen movement from root to upper part of the tree [25]. Furthermore, peach fruit moth is a severe insect of jujube. The insect lays eggs inside immature fruit by making a hole. The eggs hatch into larvae, feed on fruit pulp, and finally emerge as an adult moth. Infected fruits drop and responsible for significant yield reduction. Thus, throughout the fruiting stage, the trees should be carefully inspected to find out the symptoms. The fallen infected fruits should be destroyed to stop further spreading of pathogens. Timely spraying of pesticides could be an effective method to control peach moth [1].

\section{Conclusion}

In summary, an understanding of plant phenology helps in effective management of fruit orchard. The proposed guidelines could act as a unique tool for the phenological description of jujube. The findings further help jujube growers to recognize critical growth stages and perform management practices, including irrigation, fertilization, disease pest control, and harvesting to enhance yield and quality. Phenological documentation also aids the jujube researcher to conduct experiments in various climatic conditions.

\section{References}

1. Liu MJ (2006) Chinese jujube: Botany and horticulture. Horticultural Reviews 32: 229-298.

2. Liu MJ, Zhao J, Cai QL, et al. (2014) The complex jujube genome provides insights into fruit tree biology. Nat Commun 5: 1-12.

3. Liu MJ, Zhao ZH (2009) Germplasm resources and production of jujube in China. Acta Hort 840: 25-32.

4. San B, Yildirim N, Vildirim F, et al. (2014) A Study on micropropagation as a tool for sustainable utilization of jujube (Ziziphus jujuba Mill.) Genotypes. Journal of Science and Technology 2: 85-94.

5. Yao S (2013) Past, present, and future of jujubes--Chinese dates in the United States. HortScience 48: 672-680.

6. Outlaw WH, Zhang S, Riddle KA, et al. (2002) The jujube (Ziziphus jujuba Mill.), a multipurpose plant. Economic Botany 56: 198201.

7. Galindo A, Cruz ZN, Rodriguez P, et al. (2016) Jujube fruit water 
Citation: Sapkota S, Sapkota S, Wang S, et al. (2020) Phenological Study of Chinese Jujube Trees Using Biologische Bundesanstalt, Bundessortenamt and CHemische Industrie (BBCH) Scale. J Hortic Sci Res 3(1):68-73

relations at fruit maturation in response to water deficits. Agricultural Water Management 164: 110-117.

8. Pareek S (2013) Nutritional composition of jujube fruit. Emirates Journal of Food and Agriculture 25: 463-470.

9. Li JW, Ding SD, Ding XL (2005) Comparison of antioxidant capacities of extracts from five cultivars of Chinese jujube. Process Biochemistry 40: 3607-3613.

10. Lieth $\mathrm{H}$ (2013) Phenology and seasonality modeling. Springer Science and Business Media, 8.

11. Wei YZ, Zhang HN, Li WC, et al. (2013) Phenological growth stages of lychee (Litchi chinensis Sonn.) using the extended BBCHscale. Scientia Horticulturae 161: 273-277.

12. Salinero MC, Vela P, Sainz MJ (2009) Phenological growth stages of kiwifruit (Actinidia deliciosa 'Hayward'). Scientia Horticulturae 121: 27-31.

13. Delgado PH, Aranguren M, Reig C, et al. (2011) Phenological growth stages of mango (Mangifera indica L.) according to the BBCH scale. Scientia Horticulturae 130: 536-540.

14. Kishore K (2016) Phenological growth stages of dragon fruit (Hylocereus undatus) according to the extended BBCH-scale. Scientia Horticulturae 213: 294-302.

15. Lancashire PD, Bleiholder H, Boom TVD, et al. (1991) A uniform decimal code for growth stages of crops and weeds. Annals of Applied Biology 119: 561-601.

16. Melgarejo P, Martínez-Valero R, Guillamón JM, et al. (1997) Phenological stages of the pomegranate tree (Punka granatum L.). Annals of Applied Biology 130: 135-140.

17. Lorenz DH, Eichhorn KW, Bleiholder H, et al. (1995) Growth Stages of the Grapevine: Phenological growth stages of the grapevine
(Vitis vinifera L. ssp. vinifera)--Codes and descriptions according to the extended $\mathrm{BBCH}$ scalet. Australian Journal of Grape and Wine Research 1: 100-103.

18. Agustí M, Zaragoza S, Bleiholder H, et al. (1997) Adaptation of the $\mathrm{BBCH}$ scale for the description of Citrus fruits' phenological stages. Fruits 5: 287-295.

19. Salazar DM, Melgarejo P, Martínez R, et al. (2006) Phenological stages of the guava tree (Psidium guajava L.). Scientia Horticulturae 108: 157-161.

20. Alcaraz ML, Thorp TG, Hormaza JI (2013) Phenological growth stages of avocado (Persea americana) according to the $\mathrm{BBCH}$ scale. Scientia Horticulturae 164: 434-439.

21. Fadon E, Herrero M, Rodrigo J (2015) Flower development in sweet cherry framed in the $\mathrm{BBCH}$ scale. Scientia Horticulturae 192: 141-147.

22. Zhang HN, Sun WS, Sun GM, et al. (2016) Phenological growth stages of pineapple (Ananas comosus) according to the extended Biologische Bundesantalt, Bundessortenamt and Chemische Industrie scale. Annals of Applied Biology 169: 311-318.

23. Sapkota S, Sapkota S, Wang S, et al. (2019) Height and diameter affect survival rate of jujube suckers transplanted in a semi-arid farmland of New Mexico. Journal of Applied Horticulture 21: 249-251.

24. Jin S, Wang Y, Shi L, et al. (2018) Effects of pruning and mulching measures on annual soil moisture, yield, and water use efficiency in jujube (Ziziphus jujuba Mill.) plantations. Global Ecology and Conservation 15: 1-14.

25. Jung HY, Sawayanagi T, Kakizawa S, et al. (2003) 'Candidatus Phytoplasma ziziphi', a novel phytoplasma taxon associated with jujube witches'-broom disease. Int J Syst Evol Microbiol 53: 1037-1041.

\section{DOI: $10.36959 / 745 / 400$}

